\title{
The Impact of Climate Change on Water Resources
}

\author{
Zeyneb Kilic \\ Adiyaman University, Engineering Faculty, \\ Department of Civil Engineering, Adiyaman, Turkey \\ E-mail: zeynebboybay@gmail.com
}

\begin{abstract}
Climate change is one of today's biggest problems and a major concern and continues globally. Due to population growth, the increasing needs and industrial activities of people negatively affect most of the natural resources. Hydrology and water supply system; it is in close contact with industry, agriculture, city and economic areas, and water resources are exposed to the negative effects of climate change. The most important effect of the greenhouse effect and global warming caused by human activities and other reasons is the emergence of imbalances in the ecosystem by making the climate warmer and more variable. The negative effects of global climate change are mostly seen on water resources, agricultural activities, forest areas, sea level, soil characteristics, ecological balance, social life, energy, human health and biodiversity. Studies to examine the effects of climate change on hydrological and water resources have theoretical and realistic meanings. It is important to understand the problems in water resources, disturbances in the ecological balance and the causes of many problems caused by climate change and to know the effects of climate change on the ecosystem in order to solve them. Thus, it will be easier to develop strategies that can combat problems that may arise due to climate change today and in the future.

Turkey also between in the risk group country in terms of climate change and its adverse effects. In this study, by analyzing climate change, the causes and effects of climate change, and especially the negative effects of climate change on water resources, solution suggestions are presented in order to eliminate or minimize the negative effects that occur.
\end{abstract}

Key Words: Climate, Global warming, Climate change, Water resources.

DOI: $10.7176 /$ JSTR/6-11-07

\section{İklim Değişikliğinin Su Kaynaklarına Etkisi}

\begin{abstract}
Özet
İklim değişikliği günümüzün en büyük sorunlarından birisi ve büyük bir endişe kaynağı olup küresel olarak devam etmektedir. Nüfus artışına bağlı olarak insanların artan ihtiyaçları ve endüstriyel faaliyetleri doğal kaynakların çoğunu olumsuz yönde etkilemektedir. Hidroloji ve su kaynak sistemi; sanayi, tarım, şehir ve ekonomik alanlarla yakın ilişki içinde olup, su kaynakları iklim değişikliğinin olumsuz etkilerine maruz kalmaktadır. Başta insan faaliyetleri ve diğer sebeplerle oluşan sera etkisi ve küresel ısınmanın en önemli etkisi ikliminin daha sıcak ve daha değişken hale gelerek ekosistemde dengesizliklerin görülmesidir. Küresel iklim değişikliğinin olumsuz etkileri daha çok su kaynakları, tarımsal faaliyetler, orman alanları, deniz seviyesi, toprak özelliği, ekolojik denge, sosyal hayat, enerji, insan sağlığı ve biyoçeşitlilik üzerinde görülmektedir. İklim değişikliğinin hidrolojik ile su kaynakları üzerindeki etkilerini inceleme çalışmaları teorik ve gerçekçi anlamlara sahiptir. Su kaynaklarındaki problemleri, ekolojik dengedeki bozuklukları ve iklim değişikliğinin neden olduğu birçok sorunun nedeninin anlamak ve bunları çözebilmek için iklim değişikliğinin ekosistemdeki etkilerini bilmek önemlidir. Böylece günümüzde ve gelecekte iklim değişikliği yüzünden ortaya çıkabilecek problemlerle mücadele edebilecek stratejilerin geliştirilmesi kolaylaşacaktır.
\end{abstract}

72 | P a g e

www.iiste.org 
Türkiye'de iklim değişikliği ve olumsuz etkileri bakımından risk grubu ülkeler arasındadır. $\mathrm{Bu}$ çalışmada, iklim değişikliği, iklim değişikliği nedenleri ile etkileri, iklim değişikliğinin özellikle su kaynakları üzerindeki olumsuz etkileri analiz edilerek ortaya çıkan olumsuzlukların yok edilebilmesi veya en aza indirilebilmesi için çözüm önerileri sunulmuştur.

Anahtar Kelimeler: İklim, Küresel ısınma, İklim değişikliği, Su kaynakları.

\section{Giriş}

İklim atmosferde meydana gelen olayların uzun süreli etkisi olarak tanımlanabilir. İklim tarih boyunca farklı sebepler ve özellikle insan aktiviteleri sonucu değişme eğiliminde olmuş̧ur. İklim değişikliğinden, iklim ortalamasının on yıl veya daha uzun bir dönem parçasındaki istatistiklerinde bir veya iki önemli değişikliğin birlikte meydana geldiği durumlarda bahsedilebilir. İklim değişikliğinin etkileri çok ölçekli, çok yönlü hem olumlu hem de daha çok olumsuz olabilmektedir. İklim değişikliğinin hidrolojiye, biyolojik çeşitliliğe, ekolojiye ve ekosistemdeki değişikliklere neden olmasının yanında, ekonomiye ve sosyal yaşama da etkileri olmaktadır. İklim değişikliğinin olumsuz küresel etkileri olup özellikle ekoloji, sağlık, tarım, gıda sanayii, enerji, ulaşım, su kaynakları, sanitasyon, endüstri, madencilik gibi hassas alanları daha çok etkilemektedir. İklim değişikliği ve küresel ısınmanın artması ile orman yangınları, akarsu akış değişikliği, yağış rejimi değişikliği, su kalitesi düşüklüğü, bitki fenolojilerinde değişiklik, canlı habitatlarının zarar görmesi, kış yağışlarının azalması, buzulların daha hızlı erimesi, hidrolojik çevrim dengesizliği, zemin ve göllerdeki su hacim değişikliği, kuraklık, ekolojik bozulmalar ve buna benzer olumsuzluklar ekosistemde daha sık olmaktadır (Türkeş \& ark., 2000).

İklim değişikliği ile birlikte artan küresel sıcaklık son yüzyılda $0,6 \pm 0,2^{\circ} \mathrm{C}$ artmıştır ve artmaya devam etmektedir. "Sıcaklık artışına bağlı olarak artan atmosferik nem tutma kapasitesi yağışların daha kısa sürede daha fazla miktarda düşmesine, kuraklık periyotlarının uzayıp, taşkın ve sel olaylarının daha sıklıkla yaşanmasına sebep olmaktadır. Sıcaklık artışıyla birlikte buzullar ve karla kaplı alanlar azalmış, eriyen buzulların deniz suyuna karışmasıyla dünya hem önemli temiz su kaynaklarını kaybetmiş, hem de ısıl genleşmenin de etkisiyle yükselen su seviyesi, bazı kıyısal alanları ve ekosistemlerini tehdit etmeye başlamıştır. Yükselen deniz suyu seviyesiyle, karasal alanlarda ilerleyen tuzlu su, yeraltı su kaynakları başta olmak üzere, su kaynakları için de tehdit oluşturmaya başlamıştır" (Sandalc1, 2011). İklim değişikliğinden dolayı her geçen yıl dünyanın çeşitli yerlerinde kasırgalar, seller, kar yağışında azalma, nehir akış rejimine değişme, yeraltı suyu beslenmesinde dengesizlik, toprak verim ile kalitesinde bozulma, erozyon, buzulların erimesi, deniz seviyesinin yükselmesi, iklim kuşaklarının kayması, su kaynaklarında azalma ve aşırı yağışlar görülmektedir.

Kara ve su ekosistemlerin çoğunluğu ile canlı hayatı, gıda, tarım, enerji, sanayi, ulaşım ve atık su yönetimi belirgin şekilde suyun miktarı ve özelliğinden etkilenmektedir. Bu nedenle hidrolojik çevrim ile çevresel denge bozulması ve su kalitesinde meydana gelen düşüşün nedenleri iklim değişikliği ve diğer baskılar çerçevesinde değerlendirilmelidir. İklim değişikliğinin temiz su kaynaklarına etkisi tüm dünya nüfusunu da etkilemektedir. Şu anda dünyada bir milyardan fazla insan zaten su kitlı̆ğ olan bölgelerde yaşıyor. 2025'e kadar, dünya nüfusunun neredeyse üçte ikisinin su kıtlığından dolayı çok ciddi sıkıntı yaşayacağı tahmin edilmekte olup Türkiye'de bu hususta riskli ülkeler arasındadır. Tüm bahsedilen ve diğer nedenlerden dolayı iklim değişiminin toplum ve ekosistem üzerindeki olumlu/olumsuz etkilerinin belirlenmesine, vurgulanmasına ve olumsuz etkilerine karşı gerekli tedbirlerin alınmasına ihtiyaç vardır. Böylece gelecekte iklim değişikliği yüzünden ortaya çıkacak sorunlarla mücadele edebilecek stratejilerin geliştirilmesi hız kazanacak ve konuyla ilgili çalışmalar daha sağlıklı ve verimli yürütülebilecektir.

Bu derleme çalışmasında iklim değişikliğine etkisi olan faktörler, küresel iklim değişikliğinin özellikle su kaynakları ile diğer bazı faktörler üzerinde oluşturacağı etkiler vurgulanarak, söz konusu kaynakların etkin kullanımı ve korunmasına yönelik yaklaşım, teknik, önlem ve önerilerden bahsedilmektedir.

\section{2. İklim Değişikliği ve Su Kaynakları Arasındaki İlişsi}

Önümüzdeki 15-20 yılda Dünya nüfusunun yaklaşık \%55'nin şehirlerde yaşıyor olması ve son 50 yılda yüksek oranda artış gösteren şehirleşme iklim değişikliğine ve iklim değişikliğinin beraberinde getirdiği olumsuzluklara yol açmaktadır (Mehmet, 2004). Doğal ve insan kaynaklı pek çok faktör dünyanın sıcaklık ve enerji dengesinin değişmesine neden olabilir. İklim sistemi zamanla dış etkenler,

73 | P a g e

www.iiste.org 
insan kaynaklı faktörler kadar volkanik patlamalar, güneş sıcaklığındaki değişmeler gibi doğal olaylar etkisiyle de değişebilmektedir. Yerkürenin sıcaklığı dünyamıza giren ve dünyamızı terk eden enerji arasındaki dengeye bağlı olup; güneş ışınlarıyla dünyaya ulaşan enerjinin absorpsiyonu arttıkça dünya daha fazla ısınır, güneş ışınlarının geri yansımasıyla enerjinin atmosferde tutulmadan uzaya dönmesi ise dünyanın daha çok ısınmasına engel olur.

Küresel iklim sisteminin zamanla doğal olarak değişmesi normaldir ancak 19. yüzyılın ortalarında özellikle sanayi ile endüstrinin gelişmesi ve insan aktiviteleri ile çevre kirliliği sonucu atmosferdeki sera gazlarının birikmesi bu doğal değişime ek olarak iklimi olumsuz yönde ciddi değiştirerek yeni bir döneme girilmesine neden olmuştur. İklim değişikliği ile küresel ısınmaya karşı duyulan tedirginlikler bunların son dönemlerde en büyük, en riskli, tüm canlıları olumsuz etkileyen çevresel, tarımsal, sosyal ve ekonomik tehditlerden birisi olarak kabul edilmesinden kaynaklanmaktadır. Ekosistemin parçaları belirgin şekilde suyun miktarı ve kalitesinden etkilenmektedir (Şen, 2005). İklim değişikliği ve sebep olduğu etkiler uzun zamandır gözlenmekte ve zaman ilerledikçe daha da belirgin hale gelmektedir. Ancak iklim değişikliğinin olumsuz etkilerini engelleme konusunda belirsizlikler ile yetersizlikler bulunmaktadır. $\mathrm{Bu}$ nedenle iklim değişiminin ekosistem, ekolojik denge ve toplum üzerindeki olumlu/olumsuz etkilerinin belirlenmesi gerekmektedir. Günümüzde bahsedilen küresel iklim değişikliği ve küresel ısınma özellikle insanlarca fosil ve biyokütle yakıtlarının kullanılması gibi daha birçok sebeplerle atmosfere salınan sera gazı birikimleri nedeniyle sera etkisi oluşmakta ve bunun sonucunda yerkürenin ortalama yüzey sıcaklığında artış gözlenmekte ve neticede iklimde değişiklikler gerçekleşmektedir.

Küresel ısınma uzun yıllardan beri bilinmekte ve tartışılmaktadır, ancak küresel ısınmanın olumsuz etkilerinin ayrıntılı şekilde tartışılması konusunda ilk ciddi adım, 1979 yılında atılmıştır. Daha sonra 1980'li yıllarda konuyla ilgili düzenlenen toplantı, kongre ve konferanslar neticesinde küresel isınma ve buna bağlı olarak değişen iklimin olumsuz etkileriyle mücadelede siyasal seçeneklerin de geliştirilmesi kararına varılmıştır. Konuyla ilgili 1990'lı yıllarda da çalışmalar yapılmış olup, 1994'te yürürlüğe girmiş ve yaklaşık 184 ülke tarafından imzalanmış iklim değişikliği çerçeve sözleşmesi ile atmosferdeki sera gazı birikimlerine önlem alınabilecek düzeyde tutulması kararı alınmıştır. İklim Değişikliği Çerçeve Sözleşmesi, uluslararası düzeyde toplumun küresel iklim sistemini korumak için gerçekleştirmiş olduğu ilk önemli yasal adım olarak kabul edilmiştir. Kıyısal alanlar, yüksek nüfus yoğunluğu, deniz ticaret yoğunluğu, endemik tür barındıran sucul ekosistemleri ve ekonomik faaliyetler içermekte olup, iklim değişikliğinin olumsuz etkilerine karşı hassas olan bu bölgeler, gelecekte bu olumsuz etkilerin artmasıyla daha büyük risk altına gireceklerdir. İklim değişikliği sağlık, barınma, sosyal hayat, tarım ile gıda üretimini de etkilemekte ve iklim değişikliğinin önlenememesi durumunda daha fazla insanın olumsuz yönde etkileneceği öngörülmektedir. Ekosistem ile sosyoekonomik sistemler devletlerin kalkınması insanın yaşam kalitesinin artması için çok önemlidir ve iklim değişikliklerinden kolayca olumsuz yönde etkilenebilmektedirler.

İklim değişikliği ve su çok yakın bağlantılı olup, bilim insanlarına göre iklim değişikliğinin en önemli etkileri su döngüsünün bozulması ve su kalitesinin değişmesidir. Su kaynaklarının, suyun miktar ve kalitesinin yönetimi iklim değişikliği sebebiyle zamanla zorlaşmakta olup, iklim değişikliğinin suyu kaynakları, sanitasyon, gıda ve enerji üretimi üzerindeki etkilerinin anlaşılması ve bu kapsamda gerekli önlemlerin alınması önemlidir. İklim koşullarının su hidrolojisi ve suyun ulaşılabilirliği üzerinde büyük etkisi olup; sıcaklık, yağış, toprak nemi, atmosferik nem, hidrolojik ve iklimsel bileşenler, yağış rejimlerini doğrudan etkilemektedir ve bunların neticesinde yağış miktarında, sıklığında ve yoğunluğundaki değişim neticesinde meydana gelen sellerin, kuraklıkların, su kaynaklarında yerel ve bölgesel ölçekte büyük olumsuz etkileri olmaktadır. İklim değişikliğinin su kaynakları üzerindeki etkisi, daha çok yağış özelliklerinin değişmesinden kaynaklanmakta olup, yağışlar, yer ve zaman ölçeğinde, su dengesindeki değişkenliğin belli başlı kaynağıdır. Yağışlarda iklim değişikliği sebebi ile meydana gelen değişmelerin hidrolojik ve su kaynakları için önemli etkileri olabilmektedir. Belli bir su havzasında zamanla meydana gelen hidrolojik değişkenlik, döngüler içinde yağışlarda görülen değişkenlikten etkilenmekte olup bu durum sel sıklığı, sağnak yağ1Ş sıklığ1, kuraklık sıklığ 1 , yağıŞ azalması gibi olumsuzlukları beraberinde getirmektedir. Özellikle yağış azalması su kaynaklarını olumsuz etkileyecek ve kişi başına düşen su miktarı, nüfus artışının da etkisiyle önemli derecede azalacaktır. Kuraklığın da artmasına paralel olarak bu dönemlerde yeraltı sularının daha çok kullanılması, deniz sularının bu alanlara girmesine sebep olacak ve suyun ile ideal özelliğinin bozulmasına neden olacaktır. Kar yağışı miktarı ve zamanı değişecek, buna bağlı olarak kar örtüsü azalacak, kar erime daha erken zamana kayacak ve sonuçta çok maliyetli olan yeni su depolama yapıları ve sulama sistemlerine gerek duyulacaktır (Kanber \& ark., 2010).

74 | $P$ a g e

www.iiste.org 
Diğer taraftan çarpık şehir yapılaşmasının etkisiyle yağmur sularının toprağa sızma miktarı azalmakta, yüzeysel akışları artmakta, toprağa sızan su ile yeraltı su seviyeleri giderek azalmaktadır ve dolayısı ile su döngüsü için gerekli olan buharlaşma + terleme olayı yeterince gerçekleşmemekte ve bu durum çeşitli olumsuzluklara sebep olmaktadır. Yeraltı su seviyesinin düşmesiyle akarsuların rejimleri değişmekte bunun sonucunda da taşkın, erozyon, heyelan gibi doğal afetler daha sıklıkla görülmektedir (Sandalc1, 2011). Değişen sıcaklık, taşkın, kuraklık, hortum, şiddetli hava olayları, güneş radyasyonun artması gibi etkenler su kaynaklarında fiziko-kimyasal ve biyolojik değişikliklere neden olmakta ve böylece suyun kalitesi de düşmektedir. Küresel sıcaklıktaki artış atmosferin su tutma kapasitesini artırmakta ve su tutma kapasitesinde bu artış, atmosferik nemi arttırarak yağış rejimlerinde değişime neden olmaktadır. Buzullar ve karla kaplı alanlar iklimsel değişikliğe karşı çok duyarlı olduklarından, iklimsel değişikliklerin fark edilmesi konusunda bu alanlar önemli indikatörlerdir. 1960'tan günümüze kadar dünya genelinde karla ve buzulla kaplı alanların \%10'nun azalmış olması, iklim değişikliğinin en önemli göstergelerindendir.

Temiz su kaynaklarının ekosistem ve özellikle de canlılar açısından büyük önemi olup, bunun yanında tarım, enerji üretimi, rekreasyon ve üretim faaliyetleri için de suya ciddi anlamda ihtiyaç duyulmaktadır. İklim değişikliği, kirleticiler, ötrifikasyon gibi sebepler su kaynaklarında baskı oluşturmakta ve su kaynaklarının ve su kalitesinin giderek azalmasına neden olmaktadır. Su döngüsü, su kalitesi ve su dağılımında küresel ölçekte değişen denge, tüm canlıların, hassas ekosistemlerin, ziraat ve hayvancılıkla uğraşanların ve enerji üreticileri açısından problemlere neden olmaktadır. Türkiye koşullarında farklı amaçlar için kullanılabilecek toplam su miktarı, yaklaşık, 112 milyar $\mathrm{m}^{3}$ civarında olup, bunun $14 \mathrm{~km}^{3}$ ise yeraltı suyundan, 95 milyar $\mathrm{m}^{3}$ kadarı yurtiçi akarsulardan ve $3 \mathrm{~km}^{3}$ komşu ülkelerden elde edilmektedir (DSİ, 2009). Türkiye'de kişi başına düşen su miktarı, yıllık $1600 \mathrm{~km}^{3} / \mathrm{y} 1 \mathrm{l}$ kadar olup bu durum ülkemizin su azlığı çeken ülkeler sınıfına girdiğini göstermektedir. Endüstriyel gelişme, nüfus artışı ve su tüketiminin artması, su israfi, suyun tüketilmesindeki yanlış alışkanlıklar, su kaynaklarının kirletilmesi ve iklim değişikliği gibi nedenlerle, Dünya'da ve ülkemizdeki yıllık kişi basına düşen su miktarının daha da azalacağı öngörülmektedir. Su kaynakları ve hidrolojik döngü iklim değişikliğinin çok önemli bir parçasıdır. İklim değişikliğinin su kaynakları üzerindeki etkisi daha çok su ve su kalitesi üzerine olmaktadır. İklim değişikliği, hidrolojik döngünün mevcut durumunu değiştirmekte ve su kaynaklarının zaman ve mekanda yeniden dağılımına neden olmaktadır. Bunun yanında buharlaşma, yağış ile akış durumu, toprak nemi ve diğer faktörleri de direk etkilemektedir. Su kaynaklarının dünyadaki dağılım miktar ve yerlerinin değişmesi canlı yaşam ile yerleşim yeri dağılımını ve ekolojinin de değişmesine neden olacaktır. İklim değişikliği ile su kaynakları arasındaki ilişki şekil 1'de görülmektedir.

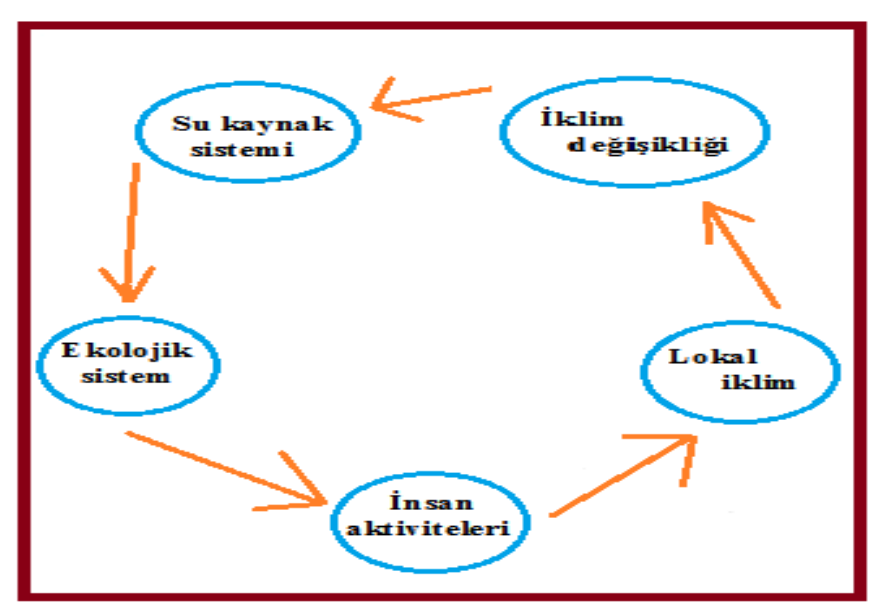

Şekil 1. İklim değişikliği ile su kaynakları arasındaki ilişki

İklim değişikliğinin su kaynakları üzerindeki etkisi konuyla ilgili birçok araştırmayı gündeme getirerek bu tür araştırmaların artmasına ve genişlemesine de neden olmuştur. 1980'li yılların ortalarında yıllarında Dünya Meteoroloji Birliği (WMO) iklim değişikliğinin hidrolojik yapı ve su kaynakları üzerine etkisini konu alan bir çalışma yayınlamışlardır (WMO, 1987). Daha sonra konuyla ilgili bazı testler ve değerlendirme metodları uygulayarak konuyla ilgili duyarlılık analiz raporu yayınlanmıştır 75 | P a g e 
(Houghton \& ark., 1995). Ancak konunun hassasiyeti ve önemi konusundaki bu tür çalş̧maların sürekli gündemde tutulup artarak devam etmesi ve bu tür çalışma sonuçlarının daha fazla uygulanması her zaman önemlidir.

\section{Sonuç ve Öneriler}

Günümüzde, Dünya nüfusunun üçte biri su stresi ile karşı karşıya olup, bu durumun daha da artacağı beklenmektedir (Fujihara \& ark., 2007). Türkiye'de ise 2030-2035 yıllarına doğru özellikle iç ve batı bölgelerde \% 40'a yakın oranda su stresi yaşanacağı tahmin edilmektedir (Harmancıŏlu \& ark., 2007). $\mathrm{Bu}$ sonuçlara göre, içme ve kullanma suyunda, tarımsal sulamada karşılaşlacak artışa karşılık su kaynaklarındaki azalma, gelecekte su kaynaklarının daha etkin yönetiminin ve daha dikkatli kullanımının zaruri olacağını göstermektedir. Bu kapsamda, sektörler arası su dağılımı, su kullanım şekli, su artırımı, su kullanımının denetimi, su kullanımı ile ilgili gözlem ağının genişletilmesi, büyük hacimli yapay depolama yapılarının arttırılması gibi konular, öncelikli olarak vakit kaybetmeden planlanmalıdır (Kanber \& ark., 2007). İklim değişikliğinin su kaynakları üzerine olan etkileri araştırıldıtan sonra su kaynaklarının yönetimi iklim değişikliği ve iklim şartları dikkate alınarak yapılmalı, komşu ülkelere ayrılacak su payları iklim değişikliği dikkate alınarak belirlenmeli, sulama yatırımları daha planlı olmalı, taşkın altında kalabilecek yerler güvenli alanlara taşınmalı, enerjiyi daha bilinçli ve verimli kullanmak ve israftan kaçınmak konusunda halk bilinci artırlarak eğitilmeli, yanlış arazi kullanımı engellenmeli, suyun toprakta tutulmasını sağlayan önlemler üzerinde durulmalı, barajlardaki buharlaşma kayıpları en aza indirecek tarzda ve yerlerde inşa edilmeli, verimli tarım topraklarının ve ekonomik değerli doğal bitkilerin baraj gölleri altında kalmaması gibi hususlara özen gösterilmelidir.

Gelecek nesillere sağlıklı ve yeterli su burakabilmesi ve kuraklıklardan korunabilmek için su kaynaklarının çok iyi korunup, akılcı kullanılması gerekmektedir. Su kaynaklarını koruma ile ilgili yaklaşımlar bölgesel olmalı, mikro ölçekte veri toplanıp modellemeler yapılmalı, uyum stratejileri yerel ölçekte geliştirilmeli, iklim, toprak ve bitki verileri sağlayan yenilikçi, sürdürülebilir sulama teknolojileri kurulmalıdır. İklim değişiminin zararlı etkilerini sınılamak ve atmosferdeki gaz salınımlarını azaltmak için uygun teknoloji geliştirmek, etkileri hafifletme seçeneklerini kullanmak, enerjiyi etkin kullanmak ve yenilenebilir enerji kaynaklarını daha fazla desteklemek gibi önlemler uygulanabilir (Venton, 2007).

Yapılan araştırmalar, etkileri hafifletme önlemlerinin; gelecek yıllarda küresel sera gazı ve küresel karbon salınımlarında beklenen artı̧ı dengeleme veya belli bir düzeyin altına indirmede, büyük bir ekonomik öneme sahip olduğunu göstermiş̧ir (Metz \& ark., 2008). Etkileri hafifletici çabaların yanında, zararları azaltmak veya iklim değişikliğinin getireceği firsatları avantaja dönüştürmek için potansiyel etkilerine karşı bir dizi tepkiyi ifade eden toplumun uyum sağlama çalışmalarından da faydalanılmalıdır. İklim değişimi konusunda halk, enerjiyi daha bilinçli ve verimli kullanmak ve israftan kaçınmak gibi konularda eğitilmelidir. Barajlar, serin iklime sahip yerlerde ve derin vadiler içerisine yapılarak, buharlaşma kayıpları en aza indirilmeli, ağaçlandırma çalışmaları yapılmalı ve verimli tarım arazileri ile biyoçeşitliliğin baraj gölleri altında kalmamasına özen gösterilmelidir (Kanber \& ark., 2010). Yeterli ve planlı önlemler alınmazsa bu yüzyıl sonunda küresel sicaklı̆̆ın ortalama 2 derece artacağ tahmin edilmektedir. Bunun sonucunda bölgesel olarak iklim değişecek, tarımsal ürünler ve ormanlar zarar görecek, toplumsal göçler başlayacak, su yüzeylerine yakın yerlerde hava nemi ve buna bağlı olarak yağışlar artacak, taşkın ve seller daha çok meydana gelecektir. Hidrolojik döngüdeki su hacminde değişiklik olmamakta olup, değişen durum hidrolojik döngüdeki sıralama ve dengesizliktir. Suyun doğal hidrolojik döngüsü ve akışının olumsuz etkilerini en aza indirebilmek için su yönetiminin çok iyi planlanması gerekmektedir. Bu amaçla içme ve kullanma suyu için kayıp/kaçak oranlarının azaltılması, yağmur suyu hasadı, tasarruflu su ekipmanlarının kullanılması, kirleticilerin zararsız hale getirilmesi, verimli sulama tekniklerinin yaygınlaştırılması, kısıntılı sulama uygulanması, organik tarım ve iyi tarım uygulaması yapılması, endüstriyel tesislerde temiz üretim uygulamalarının yaygınlaştırılması, tesis içi kontrollerin artırılması, sıfır deşarj yaklaşımının yerleştirilmesi, atık suların geri kazanılarak proses suyu ve benzeri amaçlarla yeniden kullanılması, hidroelektrik santralleri ile nükleer enerji santrallerine önem verilmesi, ağaç dikmenin özendirilmesi gibi uygulamalar yapılabilir. Ülkemiz havza temelli bütünleşik su yönetimine geçmiştir, bu durum iklim değişikliğine uyum kapsamında önemli bir adımdır. 25 havzada yönetim planlarının hazırlanması iklim değişikliğini göz önünde bulundurarak tamamlanmalı, izleme ve geliştirme çalışmaları yapılmalıdır. Havzalarda yapılacak örgütlenmelerin yanı sıra, il ve bölge bazında da yönetim planları

76 | P a g e 
uygulanmalıdır. Bütün sektör öncüleri ve paydaşların bir araya gelerek su yönetiminin karar süreçlerinde yer almaları faydalı olacaktır.

2015-2100 periyodunda Türkiye'de daha fazla görülebilecek sıcaklık artışlarından dolayı bölgelerde kuraklık ile mücadele çalışmaları geliştirilmelidir. Ağaçlandırma çalışmalarına hız vererek, su kullanımında tasarrufa giderek bu duruma karşı konmalı, halk beklenen etkiler konusunda bilinçlendirilmelidir. Olası mağduriyetleri engellemek için bu durumun tarım ürünleri, hayvancıllk ve halk sağlığı alanlarındaki etkileri bilimsel olarak incelenmeli ve bu doğrultuda önlemler alınmalıdır. Türkiye'de özellikle iklim değişikliği, küresel ısınma ve kirlilik sebebiyle gelecek yıllarda yaşanması beklenen su dağılımındaki dengesizlik, su sıkıntısı ve kuraklık karşısında, tüm sektörlerdeki su talebinin karşılanabilmesi için ciddi önlemler alınması, iklim değişikliği ile uyumlu su yönetiminin geliştirilmesi ve akılcı planlar yapılması gerekmektedir. Su konusunda araştırma, proje, geliştirme ve eğitim çalışmaları yapan kuruluşlar arasında koordinasyon sağlanması, insanların konuyla alakalı bilinç düzeylerinin artırılması ve konuyla ilgili gerekli yasal tedbirlerin alınarak tavizsiz uygulanması gerekmektedir. Tüm sektörlerde enerji verimliliğinin ve tasarrufunun artırılması; hidrolik, güneş, rüzgar, jeotermal, biyokütle, vb. yeni ve yenilenebilir enerji kaynaklarının enerji elde etmede kullanılma oranlarının artırılması; fosil yakıt tüketiminin azaltılması; ulaştırma sistemlerinin motorlu taşıtların daha az yakıt tüketmelerini sağlayabilecek biçimde düzenlenmesi ve konuyla ilgili bilinç ile farkındalığın artırılması önemlidir. Ayrıca küresel 1sınma ile birlikte hızlanan iklim değişikliğinin olumsuz etkileri her geçen yıl daha çok insanlığ 1 korkutmakta ve yaşam kalitesini düşürmektedir. Bu nedenle küresel ısınmayı önlemeye yönelik iklim ve çevre dostu politikalar ve önlemlerin ciddi şekilde uygulanmasına da zaruri ihtiyaç vardır.

\section{Kaynaklar}

Türkeş, M., Sümer, U.M., Çetiner, G. (2000). Küresel İklim Değişikliği ve Olası Etkileri, Çevre Bakanlığı, Birleşmiş Milletler İklim Değişikliği Çerçeve Sözleşmesi Seminer Notları, ÇKÖK Gn Md., Ankara. 7-24.

Mehmet, K. (2004). "Şehirleşmenin Küresel İklim Sapmaları ve Taşkınlar Üzerindeki Etkisi" Marmara Coğrafya Dergisi Sayı:6, İstanbul.

Sen, Z. (2005). İklim Değişikliği ve Su Kaynaklarına Etkisi. Dünya Su günü. İklim Değişikliğinin $\mathrm{Su}$ ve Enerji Kaynaklarına Etkisi Paneli, İstanbul, $26 \mathrm{~s}$.

Kanber, R., Bastug, R., Büyüktas, D., Ünlü, M., Kapur, B. (2010). Küresel İklim Değişikliğinin Su Kaynakları ve Tarımsal Sulamaya Etkileri, Türkiye Ziraat Mühendisliği, VII. Teknik Kongresi, Ankara.

Sandalcı, M. ve Yüksel, İ. (2011). İklim Değişikliğinin Türkiye’deki Göller ve Barajlar Üzerindeki Etkisi, Yapı Dünyası Dergisi, 181: 25-29.

DSİ. Genel Müdürlüğü., 2009. http://www.dsi.gov.tr/topraksu.htm. (09.10.2009)

WMO. (1987). Water resources and climatic change: sensitivity of water resources systems to climate change and variability. Geneva.

Houghton, J., Merra Filho L G, Caccander B (1995). IPCC Climate change 1995, the Science of Climate Change Cambridge. Cambridge University Press.

Fujihara, Y., Tanaka, T., Nagano, T., Watanabe, T., Kojiri, T. (2007). Assesing the impact of climate change on the water resources of the Seyhan River Basin-Turkey. Int. Cong., River Basin Management. Vol.I, March, Antalya-Türkiye.

Harmancıoglu, N., Fistıkoglu, O., Barbaros, F. (2007). Hidrolojik verilerin yönetiminde entegre yakalımlar. II. Ulusal Hidroloji Kongresi, İTÜ, 22-24 Haziran. İstanbul. 
Kanber, R., Kapur, B., Ünlü, M., Koç, D.L., Tekin, S. (2007). İklim Degisiminin Tarımsal Üretim Sistemleri Üzerine Etkisinin Degerlendirilmesine Yönelik Yeni Bir Yaklasım: ICCAP Projesi. Ölçü Dergisi, Eylül sayısı, s. 44-49.

Venton, C.C. (2007). Climate Change and Water Resources, Environmental Resources Manangement, Water Aid Publications.

Metz, B., Davidson, O., Bosch, P., Dave, R., Meyer, L. (2008). Climate Change Mitigation of Climate Change Contribution of Working Group III to the Fourth Assesment Report of IPPC, Cambridge University Press, Cambridge, United Kingdom and New York, USA. 851 pp. 